\title{
Reliability of the pre-operative imaging to assess neck nodal involvement in oral cancer patients, a single-center study
}

\author{
Antti L Pakkanen ${ }^{1}$, Emilia Marttila ${ }^{2}$, Satu Apajalahti ${ }^{3}$, Johanna Snäll ${ }^{2}$, Tommy Wilkman ${ }^{2}$ \\ ${ }^{1}$ MD, DDS. Department of Oral and Maxillofacial Diseases, Helsinki University Hospital and University of Helsinki, Helsinki, Finland \\ ${ }^{2}$ MD, DDS, PhD. Department of Oral and Maxillofacial Diseases, Helsinki University Hospital and University of Helsinki, \\ Helsinki, Finland \\ ${ }^{3}$ DDS, PhD. HUS Medical Imaging Center, Department of Radiology, Helsinki University Hospital, Helsinki, Finland
}

Correspondence:

Department of Oral and Maxillofacial Diseases

Helsinki University Hospital,

P.O. Box 220, FI-00029 HUS, Finland

antti.pakkanen@helsinki.fi

Received: 29/11/2021

Accepted: 07/02/2022
Pakkanen AL, Marttila E, Apajalahti S, Snäll J, Wilkman T.Reliability of the pre-operative imaging to assess neck nodal involvement in oral cancer patients, a single-center study. Med Oral Patol Oral Cir Bucal. Med Oral Patol Oral Cir Bucal. 2022 Mar 1;27 (2):e191-7.

\begin{abstract}
Background: Primary sites for the metastasis of oral cancer are the cervical lymph nodes. Although there has been considerable technical advancement in the radiological imaging, capability to recognize all metastatic lymph nodes pre-operatively has remained as a challenge. Thus elective neck dissection (END) has remained as reliable practice to treat cervical lymph nodes. This study evaluated the accuracy of pre-operative imaging in preoperative diagnostics of cervical lymph node status using computed tomography or magnetic resonance imaging in patients with oral squamous cell carcinoma (OSCC). We have also considered the reasons for the difficulties to recognise metastatic nodes in cervical area.

Material and Methods: Patient charts of patients who had had elective neck dissection as a treatment for primary OSCC in the Department of Oral and Maxillofacial Surgery, Helsinki University Hospital between 2016 and 2017 were assessed retrospectively. The outcome variable was post-operatively histologically confirmed lymph node metastasis in the neck area. The primary predictor variable was radiologically confirmed metastasis in the neck area. The explanatory variables were age, sex, pT-class, imaging modality, delay and location of the tumour. Descriptive statistics, sensitivity, specificity and Youden-J index were computed.

Results: Eighty-three patients were included in the study. The sensitivity to detect pathological lymph nodes was $44.8 \%$, and the specificity for the examination was $87.0 \% .19 .3 \%$ of cN0 patients had metastasis in the cervical nodes, whereas of the $\mathrm{cN}+$ patients $8.4 \%$ were actually $\mathrm{pN} 0$. Patients having $\mathrm{cN} 0$, the largest neck metastasis was over $10 \mathrm{~mm}$ in $12.5 \%$, whereas cN1-3 patients the corresponding rate was $45.5 \%$. The computational threshold to diagnose a metastatic node was $7 \mathrm{~mm}$.

Conclusions: Especially small metastases are difficult to diagnose. Limitations of radiological diagnostics must be considered when treating OSCC.
\end{abstract}

Key words: Oral cancer, Metastasis, CT, MRI, Neck dissection. 


\section{Introduction}

Cervical lymph nodes are the primary site of metastasis in oral carcinoma. Malignant involvement of lymph nodes is the most important independent prognostic factor in oral carcinoma and decreases the 5-year survival significantly $(1,2)$. Previously, the only reliable way to detect cervical lymph node metastases in oral carcinoma was to perform an elective neck dissection (END) $(3,4)$. Other practices have been to reserve neck dissection for a salvage procedure in case of later metastasis. However, patients with salvage neck dissection often have an increased number of positive nodes and extracapsular spread, and therefore, require a more radical neck dissection, resulting in increased morbidity $(5,6)$.

The current accepted practice is to perform an END when the risk of nodal metastasis is estimated to exceed 20\% (7). A recent meta-analysis considered END to be superior to observation in patients with early stage cT1/T2N0 tongue cancer (8). However, even if END improved disease-specific survival rate, it remained non-significant for disease-free survival and cervical nodal recurrence. It has also been shown that approximately $70-80 \%$ of $\mathrm{cN} 0$ oral carcinoma patients receive no benefit from END $(5,9,10)$, and sentinel lymph node biopsy is recommended instead (11). This emphasizes the importance of predicting post-operative staging by pre-operative means as accurately as possible. Particularly important is the reliability of pre-operative cervical lymph node staging.

Contrast-enhanced computed tomography (CT), magnetic resonance imaging (MRI) and ultrasound are standard tools employed in many centres to detect local metastatic lymph nodes. Imaging has been shown to be superior to clinical palpation of the neck area (12). Despite this, clinically and radiologically undetectable occult metastases are present in up to $20-46 \%$ of $\mathrm{cN} 0$ oral carcinomas $(2,13-15)$. No consensus has been reached regarding superiority between the different imaging techniques $(16,17)$. According to previous studies, they offer similar diagnostic accuracy in detecting nodal metastases. Pre-operative radiological staging plays a significant role in the choice of treatment offered to patients.

The aim of this retrospective study was to analyse the accuracy of pre-operative imaging in pre-operative diagnostics of cervical lymph node status using CT or MRI in patients with oral squamous cell carcinoma (OSCC). Our hypothesis was that radiological lymph node status predicts the result of histopathological analysis of the neck dissection sample.

\section{Material and Methods}

- Study design

We designed and implemented a cross-sectional retro- spective study in which we assessed patient charts of all patients who had had END as a treatment for primary OSCC in the Department of Oral and Maxillofacial Surgery, Helsinki University Hospital between 2016 and 2017.

We included patients with clinically and histopathologically confirmed primary OSCC. Exclusion criteria were prior radiotherapy or chemotherapy, unknown primary tumour or earlier malignancies of the head and neck area.

- Study variables

The outcome variable was post-operatively histologically confirmed lymph node metastasis in the neck area. The primary predictor variable was radiologically confirmed metastasis in the neck area.

In addition, a threshold value for a detected positive lymph node was calculated. The explanatory variables were age, sex, pT-class, imaging modality (CT or MRI or both), delay (time from imaging to surgery) and location of the tumour (according to ICD10 classification).

- Tumour staging

Diagnosis and tumour staging of all patients were confirmed by the multi-disciplinary head and neck tumour board of Helsinki University Hospital. At least two head and neck radiologists analysed each preoperative radiological image and the pre-operative staging and treatment plan was decided according to consensus of the multi-disciplinary meeting (Finnish National Guidelines for Treatment of OSCC and TNM Classification of Malignant Tumors 7th ed UICC). The final histopathological diagnosis and staging were set by the multi-disciplinary head and neck tumour team. - Imaging

MRI was performed using either a $1.5 \mathrm{~T}$ unit (Magnetom Vision; Siemens, Erlargen, Germany) or a $3 \mathrm{~T}$ unit (Magnetom Vision; Siemens, Erlangen, Germany or Philips Medical Systems). CT was performed using General Electric BrightSpeed or LightSpeed. Both MRI and CT were performed in contrast-enhanced mode. Slice thickness of the reformats ranged from 1.0 $\mathrm{mm}$ to $3.0 \mathrm{~mm}$.

- Radiological lymph node status criteria

The lymph node status was based on a radiological statement achieved by pre-operative imaging using CT or MRI or both. The two major imaging criteria used were nodal size and the presence of central nodal necrosis or nodal heterogeneity. We used the minimum axial diameter of the lymph node, with normal nodes not exceeding $11 \mathrm{~mm}$ in the jugulodigastric region and $10 \mathrm{~mm}$ elsewhere in the neck and head (18-20). In addition, a retropharyngeal node was considered normal if it did not exceed $8 \mathrm{~mm}$ in maximum diameter or $5 \mathrm{~mm}$ in short-axis diameter (21). Size criteria for metastatic lymph nodes are presented in Table 1. 
Table 1: Criteria for metastatic lymph node according to the region of the neck.

\begin{tabular}{|l|l|}
\hline Region & Minimum axial diameter of lymph node \\
\hline Jugulodigastric region & $11 \mathrm{~mm}$ \\
\hline Retropharyngeal region & $\begin{array}{l}8 \mathrm{~mm} \text { in maximum diameter or } 5 \mathrm{~mm} \text { in short-axis } \\
\text { diameter }\end{array}$ \\
\hline Other region & $10 \mathrm{~mm}$ \\
\hline $\begin{array}{l}\text { Additional criteria for metastatic lymph node: } \\
\text { Central region of low attenuation (10 to 25 Houndsfield units) }\end{array}$ & with thick and variably enhanced nodal rim. \\
\hline
\end{tabular}

On contrast-enhanced imaging, necrotic nodes have a central region of low attenuation (10 to $25 \mathrm{HU}$ ) with a thick and variably enhanced nodal rim and usually high signal intensity on T2-weighted images corresponding to necrosis.

- Statistical analysis

Statistical analysis was conducted with IBM SPSS 26. Two-tailed t-test was used to compare descriptive statistics of the groups pN0 and pN1-3. Youden-J index was calculated for patients having metastasis in the neck area. The cut-off value for the size of the detected metastasis was estimated. We estimated the sample size of statistical significance for the observed system with parameters for lowest acceptable sensitivity of $45 \%$ and specificity of $85 \%$, confidence interval of $5 \%$ and with $35 \%$ of incidence of the metastasis (22).

\section{Results}

A total of 102 patients treated with END for primary oral cancer between 2016 and 2017 were identified from the database of the Department of Oral and Maxillofacial Diseases. Ten patients were excluded for previous surgery of the neck region, 6 patients for malignancy other than oral carcinoma, two patients for unknown primary tumour and one patient due to indistinct radiological statement. Thus, a total of 83 patients were included in the final analyses.

Descriptive statistics of the patients are presented in Table 2. The most common tumour size was pT4. None of the included patients had pT3 tumour. The median ages of patients with pN0 (no cervical metastasis found in histopathological analysis) and pN1-3 (metastasis found in the histopathological analysis) were 68.9 and 70.0 years, respectively. CT and MRI were used to characterize the tumour and the neck area, with $\mathrm{CT}$ being the most frequently used. Two patients examined with both CT and MRI were included in the MRI group for further analyses.

Most of the patients received surgery within 30 days of imaging (median 22 days). Comparing the two groups, pN0 vs. pN1-3, the delay was almost equal. Additionally, a delay of over 30 days did not affect the final lymph node status. Other differences between the examined study variables and final lymph node status remained non-significant.

For the whole population with pT1-4 (CT and MRI scan), the sensitivity to detect a real positive lymph node was $44.8 \%$ and the specificity to rule out a negative lymph node was $87.0 \% .19 .3 \%$ of $\mathrm{cN} 0$ patients had $\mathrm{pN}+$, whereas of the $\mathrm{cN}+$ patients $8.4 \%$ were actually pN0 (Table 3).

Comparing CT and MRI, the sensitivity of the former was $45.5 \%$ and of the latter $42.9 \%$ when we analysed the whole group of pT1-4. The corresponding specificity values were $86.8 \%$ and $87.5 \%$ (Table 4 ).

We also conducted a comparison of smaller tumours (pT1 and pT2) and larger tumours (pT4). The sensitivity for detecting a positive lymph node was $33.3 \%$ for smaller tumours and $57.1 \%$ for larger tumours. On the other hand, the specificity for detecting a positive lymph node was $93.9 \%$ for smaller tumours and $76.2 \%$ for larger tumours.

Differences between lymph node status and size of the largest histological metastasis are presented in Fig. 1. In $12.5 \%$ of patients with $\mathrm{cN} 0$, the largest neck metastasis was over $10 \mathrm{~mm}$, whereas in cN1-3 patients the corresponding rate was $45.5 \%$. However, also metastasis of $5 \mathrm{~mm}$ or below occurred in this population (10.8\%). Using the Youden-J parameter, we estimated that the cut-off value for the radiologist to correctly identify a metastasis in the patient was 7 $\mathrm{mm}$. The sample size for the observed group would have been 1087 patients to gain power to have statistical significance. 
Table 2: Descriptive statistics of 83 oral carcinoma patients with neck dissection and associations with pathological lymph node status.

\begin{tabular}{|c|c|c|c|c|c|c|}
\hline & & \multicolumn{2}{|c|}{ pNo } & \multicolumn{2}{|c|}{ pN1 or more } & $p$-value \\
\hline & & \multicolumn{2}{|c|}{ years } & \multicolumn{2}{|c|}{ years } & \\
\hline \multirow[t]{4}{*}{ Age } & Range & \multicolumn{2}{|c|}{23.7 to 89.3} & \multicolumn{2}{|c|}{47.4 to 94.3} & \multirow{3}{*}{$p=0.16$} \\
\hline & Mean & \multicolumn{2}{|c|}{66.4} & \multicolumn{2}{|c|}{70.6} & \\
\hline & Median & \multicolumn{2}{|c|}{68.9} & \multicolumn{2}{|c|}{70.0} & \\
\hline & & $\begin{array}{c}\text { No. of } \\
\text { patients }\end{array}$ & $\begin{array}{c}\% \text { of } \\
\text { patients } \\
\text { with pNO }\end{array}$ & $\begin{array}{c}\text { No. of } \\
\text { patients }\end{array}$ & $\begin{array}{c}\% \text { of patients } \\
\text { with pN1 or } \\
\text { more }\end{array}$ & \\
\hline \multirow[t]{2}{*}{ Sex } & Male & 27 & 50 & 17 & 58.6 & \multirow{2}{*}{$p=0.46$} \\
\hline & Female & 27 & 50 & 12 & 41.4 & \\
\hline \multirow[t]{4}{*}{ T-class } & $\mathrm{T} 1$ & 16 & 29.6 & 8 & 27.6 & \multirow{4}{*}{$p=0.50$} \\
\hline & $\mathrm{T} 2$ & 17 & 31.5 & 7 & 24.1 & \\
\hline & $\mathrm{T} 3$ & 0 & 0.0 & 0 & 0.0 & \\
\hline & $\mathrm{T} 4$ & 21 & 38.9 & 14 & 48.3 & \\
\hline \multirow{3}{*}{$\begin{array}{l}\text { Imaging } \\
\text { modality }\end{array}$} & MRI & 15 & 27.8 & 6 & 20.7 & \multirow{3}{*}{$p=0.75$} \\
\hline & $\mathrm{CT}$ & 38 & 70.4 & 22 & 75.9 & \\
\hline & MRI and CT & 1 & 1.8 & 1 & 3.4 & \\
\hline \multirow{5}{*}{$\begin{array}{l}\text { Delay from } \\
\text { imaging to } \\
\text { surgery (days) }\end{array}$} & Range & 2 to 48 & & 7 to 71 & & \multirow{5}{*}{$p=0.85$} \\
\hline & Mean & 24 & & 23 & & \\
\hline & Median & 22 & & 22 & & \\
\hline & 30 days or under & 39 & $72.2 \%$ & 24 & $82.8 \%$ & \\
\hline & more than 30 days & 15 & $27.8 \%$ & 5 & $17.2 \%$ & \\
\hline \multirow{7}{*}{$\begin{array}{l}\text { Location of } \\
\text { tumour (ICD10) }\end{array}$} & C00, Lip & 1 & $1.9 \%$ & 0 & $0.0 \%$ & \multirow{7}{*}{$p=0.18$} \\
\hline & C02, Tongue & 18 & $33.3 \%$ & 5 & $17.2 \%$ & \\
\hline & C03, Gingiva & 21 & $38.9 \%$ & 9 & $31.0 \%$ & \\
\hline & C04, Floor of mouth & 6 & $11.1 \%$ & 5 & $17.2 \%$ & \\
\hline & C05, Palate & 2 & $3.7 \%$ & 3 & $10.3 \%$ & \\
\hline & C06, Vestibulum and retromolar & 5 & $9.3 \%$ & 7 & $24.1 \%$ & \\
\hline & C09, Tonsil & 1 & $1.9 \%$ & 0 & $0.0 \%$ & \\
\hline
\end{tabular}

Statistical significance at $\mathrm{p}<0.05 ; \mathrm{CT}=$ computed tomography; $\mathrm{MRI}=$ magnetic resonance imaging

Table 3: Radiological and histopathological lymph node status in 83 oral carcinoma patients. Sensitivity and specificity for CT and MRI, pT1-4.

\begin{tabular}{|c|c|c|c|c|c|c|c|c|c|}
\hline \multicolumn{10}{|c|}{ Histopathological lymph node status } \\
\hline \multirow{2}{*}{\multicolumn{2}{|c|}{$\begin{array}{l}\text { Radiological } \\
\text { lymph node } \\
\text { status }\end{array}$}} & \multicolumn{2}{|c|}{ No } & \multicolumn{2}{|c|}{ N1 or more } & \multirow[b]{2}{*}{ Sensitivity } & \multirow[b]{2}{*}{ Specificity } & \multirow[b]{2}{*}{$\begin{array}{l}\text { Positive } \\
\text { predictive } \\
\text { value }\end{array}$} & \multirow[b]{2}{*}{$\begin{array}{c}\text { Negative } \\
\text { predictive } \\
\text { value }\end{array}$} \\
\hline & & $\begin{array}{c}\text { No. of } \\
\text { patients }\end{array}$ & $\begin{array}{c}\% \text { of } \\
\text { patients }\end{array}$ & $\begin{array}{c}\text { No. of } \\
\text { patients }\end{array}$ & $\begin{array}{l}\% \text { of pa- } \\
\text { tients with } \\
\text { pN1 or }\end{array}$ & & & & \\
\hline pT1-4 & No & 47 & $56.6 \%$ & 16 & $19.3 \%$ & \multirow[b]{2}{*}{$44.8 \%$} & \multirow[b]{2}{*}{$87.0 \%$} & \multirow[b]{2}{*}{$65.0 \%$} & \multirow[b]{2}{*}{$74.6 \%$} \\
\hline & $\begin{array}{l}\text { N1 or } \\
\text { more }\end{array}$ & 7 & $8.4 \%$ & 13 & $15.7 \%$ & & & & \\
\hline
\end{tabular}


Table 4: Radiological and histopathological lymph node status in 83 oral carcinoma patients. Sensitivity and specificity for CT or MRI imaging, pT1-4.

\begin{tabular}{|c|c|c|c|c|c|c|c|c|c|}
\hline \multicolumn{10}{|c|}{ Histopathological lymph node status } \\
\hline \multirow{2}{*}{\multicolumn{2}{|c|}{$\begin{array}{l}\text { Radiological lymph } \\
\text { node status }\end{array}$}} & \multicolumn{2}{|c|}{ No } & \multicolumn{2}{|c|}{ N1 or more } & \multirow[b]{2}{*}{$\begin{array}{l}\text { Sensitiv- } \\
\text { ity }\end{array}$} & \multirow[b]{2}{*}{$\begin{array}{l}\text { Specific- } \\
\text { ity }\end{array}$} & \multirow[b]{2}{*}{$\begin{array}{c}\text { Positive } \\
\text { predictive } \\
\text { value }\end{array}$} & \multirow[b]{2}{*}{$\begin{array}{c}\text { Negative } \\
\text { predictive } \\
\text { value }\end{array}$} \\
\hline & & No. of & $\begin{array}{l}\% \text { of pa- } \\
\text { tients with }\end{array}$ & No. of & $\begin{array}{l}\% \text { of pa- } \\
\text { tients with }\end{array}$ & & & & \\
\hline \multirow{2}{*}{$\begin{array}{l}\text { pT1-4, } \\
\text { CT }\end{array}$} & N0 & 33 & $55.0 \%$ & 12 & $20.0 \%$ & \multirow[b]{2}{*}{$45.5 \%$} & \multirow[b]{2}{*}{$86.8 \%$} & \multirow[b]{2}{*}{$66.7 \%$} & \multirow[b]{2}{*}{$73.3 \%$} \\
\hline & $\begin{array}{l}\text { N1 or } \\
\text { more }\end{array}$ & 5 & $8.3 \%$ & 10 & $16.7 \%$ & & & & \\
\hline \multirow{2}{*}{$\begin{array}{c}\text { pT1-4, } \\
\text { MRI }\end{array}$} & N0 & 14 & $60.9 \%$ & 4 & $17.4 \%$ & \multirow[b]{2}{*}{$42.9 \%$} & \multirow[b]{2}{*}{$87.5 \%$} & \multirow[b]{2}{*}{$60.0 \%$} & \multirow[b]{2}{*}{$77.8 \%$} \\
\hline & $\begin{array}{l}\mathrm{N} 1 \text { or } \\
\text { more }\end{array}$ & 2 & $8.7 \%$ & 3 & $13.0 \%$ & & & & \\
\hline
\end{tabular}

Patients with CT and MRI are included in the MRI group.

$\mathrm{CT}=$ computed tomography; MRI=magnetic resonance imaging.
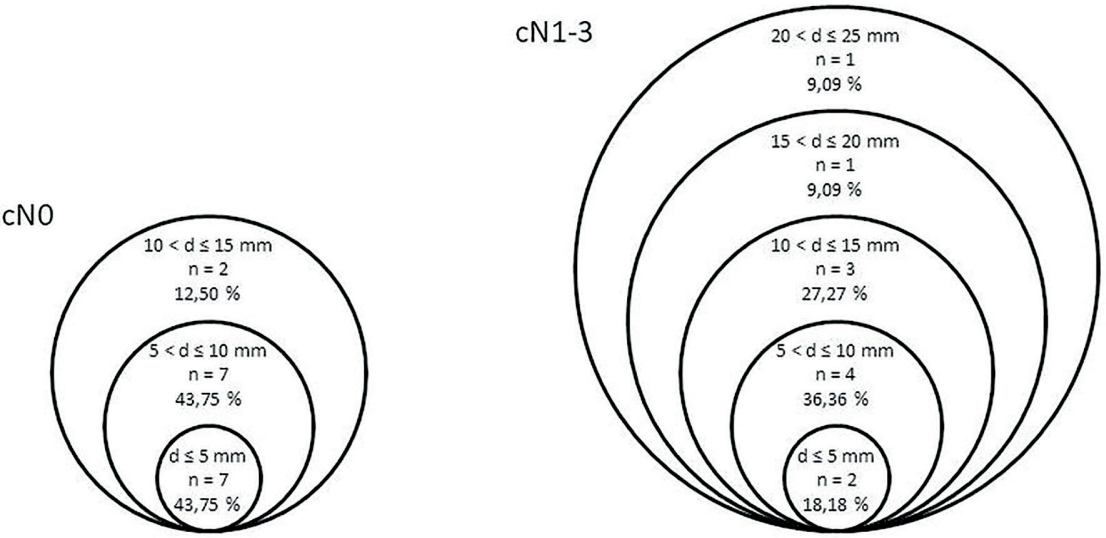

Fig. 1: Size of the largest metastatis found post-operatively in histopathological analysis. Patients with pT1-4 examined with CT or MRI scan. Diameter of the largest metastasis is indicated by (d) and number of patients by (n).

\section{Discussion}

The ability of pre-operative imaging to detect metastatic lymph nodes among patients with OSCC was examined. Our hypothesis was that radiological lymph node status predicts the final cervical lymph node status. The results confirmed the hypothesis only partially. In our population, the sensitivity to diagnose a metastatic lymph node was $44.8 \%$ (Fig. 2).

Diagnostics for small metastasis in the neck area remains a challenge. Size criteria for metastatic lymph nodes originate from studies from the 1980s and 1990s (18-20). No notable changes have occurred in recent years in the diagnostic criteria for metastatic lymph nodes (23). While enormous advances have been made in radiological equipment, occult metastases still occur in $20-40 \%$ of patients with OSCC (24). Our study highlights the challenges in clinical decision-making, as a reliable method for assessing cervical lymph node status remains to be developed (6).

Earlier studies have indicated the superiority of imaging over clinical examination and palpation (6). The sensitivity of CT ranges from $47 \%$ to $80 \%$ and the specificity from $88.9 \%$ to $99 \%(17,25)$, whereas the sensitivity of MRI ranges from $57 \%$ to $93 \%$ and the specificity from $82.5 \%$ to $99 \%(16,17,25)$. PET-CT (Positron Emission Tomography Computed Tomography) has not affected the outcome of imaging significantly (23). Our results highlight the limitations in predicting status of metastatic lymph nodes in the neck area. Up to $44 \%$ of cN0 patients have been shown to have occult metastases (23). 


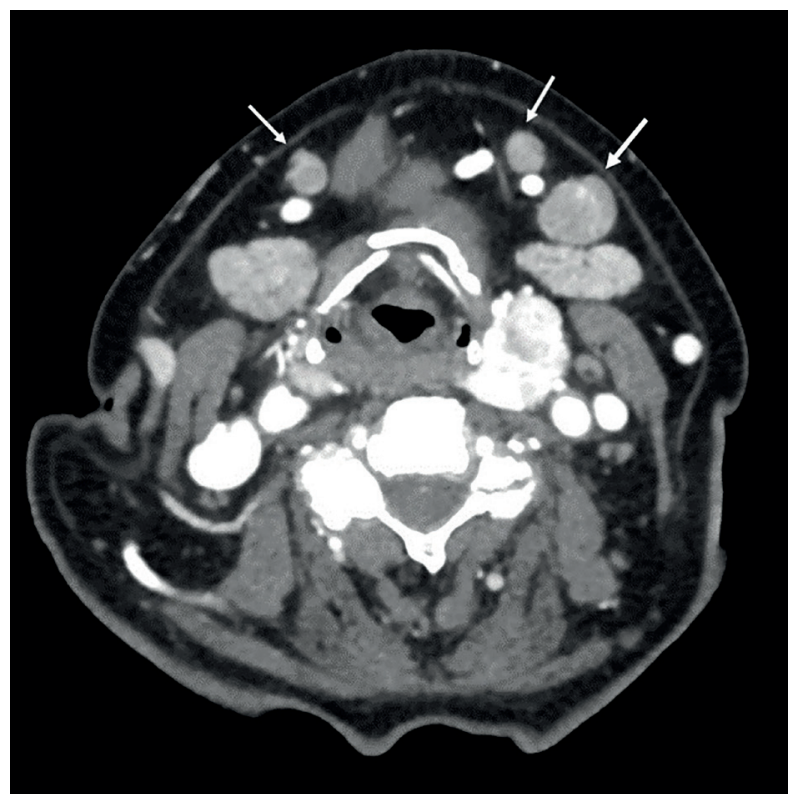

Fig. 2: Contrast enhanced computed tomography of a patient with cT3 tongue squamous cell carcinoma on the left side showed a prominent suspicious left submandibular lymph node (large arrow). In addition, smaller rounded lymph nodes were evident bilaterally (small arrows). In spite of radiological findings, metastatic lymph nodes were not detected in postoperative histopathological examination after the elective neck dissection. A prominent thyroid was diagnosed as an incidental finding.

In our study, $19.3 \%$ of $\mathrm{cN} 0$ patients had $\mathrm{pN}+$, whereas of the $\mathrm{cN}+$ patients $8.4 \%$ were actually $\mathrm{pN} 0$. Most of the nodes that were not detected in pre-operative imaging were smaller than $10 \mathrm{~mm}$. According to our results, the difficulty in assessing metastatic lymph nodes appears to be related to the size of the metastasis. The computational threshold for an undetected metastasis was $7 \mathrm{~mm}$. These findings were consistent even though the CT and MRI scans were analysed by highly experienced head and neck radiologists and the treatment plans were assessed in a multi-disciplinary meeting.

Although there are challenges in pre-operative radiological evaluation and in detection of small metastases, particularly those under $7 \mathrm{~mm}$, pre-operative imaging yields valuable information. Tumour diameter and depth of invasion correlate with histopathological data (26), and imaging is an important component in treatment planning. Skip metastases are rarely seen in neck regions, and thus, one can consider not treating LIV and LV regions in patients without suspicious lymph nodes in pre-operative imaging (24). Additionally, pre-operative imaging helps the surgeon to dissect metastatic lymph nodes involving vital structures in the neck area. Our study showed higher N1-3 sensitivity in T4 patients than in patients with other tumours. Depth of invasion, micro-metastases and type of growth of the tumour have an effect on the lymph node status found in histo- logical analysis (23). Therefore, it can be assumed that the radiologist is prone to upgrade a suspicious node that would be classified as N0 in a smaller T class. Surgical delay may also lead to differences between radiological staging and final lymph node status. However, in this study, we did not find any significant association between delay of surgery and the final staging.

We examined our patients with up-to-date radiological equipment and used a consistent treatment protocol. Nevertheless, occult metastases were detected. CT and MRI clearly have limitations. Ultrasound scan and PET-CT have been also used to detect metastatic lymph nodes in the head and neck area, but have not proven superior $(23,27)$. Investigations of artificial intelligence in the analysis of radiological data are underway (28).

The main limitation of our study is its retrospective study design. The size of our material also sets limitations on comparison of subgroups with statistical significance, thus the study has to be considered as descriptive. Moreover, we cannot prove that a lymph node detected radiologically is the same one that is diagnosed in histological analysis.

In sum, our study supports the current praxis of treating cervical lymph nodes with END while treating OSCC. Improvements in radiological diagnostics are needed to detect occult metastasis in OSCC. The limitations of radiological diagnostics must be considered when devising a surgical treatment plan.

\section{References}

1. Broglie MA, Haerle SK, Huber GF, Haile SR, Stoeckli SJ. Occult metastases detected by sentinel node biopsy in patients with early oral and oropharyngeal squamous cell carcinomas: impact on survival. Head Neck. 2013;35:660-6.

2. Schilling C, Stoeckli SJ, Haerle SK, Broglie MA, Huber GF, Sorensen JA, et al. Sentinel European Node Trial (SENT): 3-year results of sentinel node biopsy in oral cancer. Eur J Cancer. 2015;51:2777-84. 3. Crile G. Landmark article Dec 1, 1906: Excision of cancer of the head and neck. With special reference to the plan of dissection based on one hundred and thirty-two operations. By George Crile. JAMA. 1987;258:3286-93.

4. Shah JP. Patterns of cervical lymph node metastasis from squamous carcinomas of the upper aerodigestive tract. Am J Surg. 1990;160:405-9.

5. Hutchison IL, Ridout F, Cheung SMY, Shah N, Hardee P, Surwald $\mathrm{C}$, et al. Nationwide randomised trial evaluating elective neck dissection for early stage oral cancer (SEND study) with meta-analysis and concurrent real-world cohort. Br J Cancer. 2019;121:827-36.

6. Pantvaidya G, Rao K, D'Cruz A. Management of the neck in oral cancers. Oral Oncol. 2020;100:104476.

7. Weiss MH, Harrison LB, Isaacs RS. Use of decision analysis in planning a management strategy for the stage N0 neck. Arch Otolaryngol Head Neck Surg. 1994;120:699-702.

8. Alsini AY, Alsubaie HM, Marzouki HZ, Abu-Zaid A, Al-Qahtani $\mathrm{K}$. Elective node dissection versus observation for management of patients with early-stage cT1/T2N0 tongue carcinoma: A systematic review and meta-analysis of prospective studies. Clin Otolaryngol. 2021;46:720-8.

9. Hernando J, Villarreal P, Alvarez-Marcos F, Gallego L, GarcíaConsuegra L, Junquera L. Comparison of related complications: sentinel node biopsy versus elective neck dissection. Int J Oral Maxillofac Surg. 2014;43:1307-12. 
10. Cramer JD, Sridharan S, Ferris RL, Duvvuri U, Samant S. Sentinel lymph node biopsy versus elective neck dissection for stage I to II oral cavity cancer. Laryngoscope. 2019;129:162-9.

11. Marttila E, Keski-Säntti H, Hagström J, Snäll J, Wilkman T. Sentinel lymph node biopsies in early stage oral and oropharyngeal carcinoma: a retrospective single-centre experience. Br J Oral Maxillofac Surg. 2020;58:1078-83.

12. Merritt RM, Williams MF, James TH, Porubsky ES. Detection of cervical metastasis. A meta-analysis comparing computed tomography with physical examination. Arch Otolaryngol Head Neck Surg. 1997:123:149-52.

13. Arya S, Rane P, Deshmukh A. Oral cavity squamous cell carcinoma: role of pretreatment imaging and its influence on management. Clin Radiol. 2014;69:916-30.

14. Pedersen NJ, Jensen DH, Hedbäck N, Frendø M, Kiss K, Le1 kaitis G, et al. Staging of early lymph node metastases with the sentinel lymph node technique and predictive factors in T1/T2 oral cavity cancer: A retrospective single-center study. Head Neck. 2016;38:E1033-40.

15. Hingsammer L, Seier T, Zweifel D, Huber G, Rücker M, Bredell M, et al. Sentinel lymph node biopsy for early stage tongue cancer - a 14 - year single-centre experience. Int J Oral Maxillofac Surg. 2019;48:437-42.

16. Wu L-M, Xu J-R, Liu M-J, Zhang X-F, Hua J, Zheng J, et al. Value of magnetic resonance imaging for nodal staging in patients with head and neck squamous cell carcinoma: a meta-analysis. Acad Radiol. 2012;19:331-40.

17. Liao L-J, Hsu W-L, Wang C-T, Lo W-C, Lai M-S. Analysis of sentinel node biopsy combined with other diagnostic tools in staging $\mathrm{cN} 0$ head and neck cancer: A diagnostic meta-analysis. Head Neck. 2016;38:628-34.

18. Som PM. Detection of metastasis in cervical lymph nodes: CT and MR criteria and differential diagnosis. AJR Am J Roentgenol. 1992;158:961-9.

19. Stevens MH, Harnsberger HR, Mancuso AA, Davis RK, Johnson LP, Parkin JL. Computed tomography of cervical lymph nodes. Staging and management of head and neck cancer. Arch Otolaryngol. 1985;111:735-9.

20. van den Brekel MW, Stel HV, Castelijns JA, Nauta JJ, van der Waal I, Valk J, et al. Cervical lymph node metastasis: assessment of radiologic criteria. Radiology. 1990;177:379-84.

21. Mancuso AA, Harnsberger HR, Muraki AS, Stevens MH. Computed tomography of cervical and retropharyngeal lymph nodes: normal anatomy, variants of normal, and applications in staging head and neck cancer. Part I: normal anatomy. Radiology. 1983;148:709-14. 22. Jones SR, Carley S, Harrison M. An introduction to power and sample size estimation. Emerg Med J. 2003;20:453-8.

23. Furukawa M, Dillon JK, Futran ND, Anzai Y. The prevalence of lymph node metastases in clinically N0 necks with oral cavity squamous cell carcinoma: is CT good enough for nodal staging? Acta Radiol. 2014;55:570-8.

24. Vassiliou LV, Acero J, Gulati A, Hölzle F, Hutchison IL, Prabhu $\mathrm{S}$, et al. Management of the clinically N0 neck in early-stage oral squamous cell carcinoma (OSCC). An EACMFS position paper. J Craniomaxillofac Surg. 2020;48:711-8.

25. Souren C, Kloss-Brandstätter A, Stadler A, Kross K, Yamauchi $\mathrm{K}$, Ketelsen $\mathrm{D}$, et al. Ultrasound-guided fine-needle aspiration cytology as a diagnostic tool in comparison to ultrasound and MRI for staging in oral- and oropharyngeal squamous cell tumors. J Craniomaxillofac Surg. 2016;44:197-201.

26. Huopainen P, Jouhi L, Hagström J, Apajalahti S. MRI correlates to histopathological data in oral tongue squamous cell carcinoma diagnostics. Acta Odontol Scand. 2021;79:161-6.

27. Kowalski LP, Sanabria A. Elective neck dissection in oral carcinoma: a critical review of the evidence. Acta Otorhinolaryngol Ital. 2007;27:113-7.

28. Ariji Y, Fukuda M, Nozawa M, Kuwada C, Goto M, Ishibashi K, et al. Automatic detection of cervical lymph nodes in patients with oral squamous cell carcinoma using a deep learning technique: a preliminary study. Oral Radiol. 2021;37:290-6.

\section{Funding}

The present study has no funding.

\section{Conflict of interest}

The authors have no conflicts of interest to disclose.

Ethics

The internal review board of the Head and Neck Center, Helsinki University Hospital (HUS/66/2018) approved the study. Patient permission was not obtained. We have followed the guidelines of the Helsinki Declaration in this study.

\section{Authors contributions}

A.P.: Conceptualization, data collection, statistical analysis, writing. E.M.: Methodology, writing, review and editing.

S.A.: Methodology, writing, review and editing.

J.S.: Methodology, project supervision, writing and editing.

T.W.: Conceptualization, methodology, project supervision, writing and editing.

All authors read and approved the final version of the manuscript. 